\title{
The $65-\mathrm{kD}$ subunit of NF- $\mathrm{KB}$ is a receptor for IKB and a modulator of DNA-binding specificity
}

\author{
Manuela B. Urban and Patrick A. Baeuerle ${ }^{1}$ \\ Laboratorium für Molekulare Biologie der Ludwig-Maximilians-Universität München, Genzentrum D-8033 Martinsried, \\ Germany
}

\begin{abstract}
A recent study has shown that the dimeric form of the 50-kD DNA-binding subunit of the NF-kB transcription factor is commonly associated with two molecules of a $65-\mathrm{kD}$ protein (p65) and that p65 appears to be required for inactivation of the $\mathbf{p 5 0}$ dimer by the inhibitory subunit IKB. Here, we provide evidence that p65 serves as a receptor for IкB. Preincubation of IKB with purified p65 prevented IкB from inactivating the heterotetrameric form of NF-kB. Furthermore, excess p65 could very efficiently activate the latent form of NF- $\mathrm{B}$ composed of p50, p65, and IKB, presumably by binding the IKB, which was released from the complex due to its inherent off rate. An additional function of p65 in modulating the DNA-binding specificity of p50 was found. In the absence of p65, p50 could bind with high affinity to completely palindromic sites. The heterotetramer recognized these sites with an affinity $>10$-fold lower but preferred the less symmetric physiological $\kappa B$ site. The affinity of p50 for the most frequent $\kappa B$ motif 5'-GGGACTTTCC-3' was enhanced twofold by p65 to yield a dissociation constant of $\sim 4 \times 10^{-13} \mathrm{M}$. This study describes novel functions for a non-DNA-binding accessory protein of a transcription factor in controlling its inducibility and DNA-binding specificity.
\end{abstract}

[Key Words: NF-кB; IкB; 65-kD subunit of NF-кB]

Received July 2, 1990; revised version accepted August 27, 1990.

NF- $\mathrm{kB}$ is a protein that can potently initiate transcription of genes upon binding to decameric sequence motifs in enhancer and promoter elements (Sen and Baltimore 1986a,b; Lenardo et al. 1987; Kawakami et al. 1988; Pierce et al. 1988; for reviews, see Lenardo and Baltimore 1989; Baeuerle and Baltimore 1990). A common characteristic of the proteins encoded by the target genes of NF- $\mathrm{kB}$ is their involvement in immediate early processes of immune response, infection, inflammation, and acute phase response (Baeuerle and Baltimore 1990; Libermann and Baltimore 1990). Many cytokine genes and those encoding immunoregulatory cell-surface receptors are inducibly regulated by the transcription factor, and some viruses utilize NF-кB for inducing their own expression. NF- $\mathrm{B}$ can activate genes very rapidly because dissociation from the inhibitory subunit IкB is the sole event required for triggering activation of the protein (Baeuerle and Baltimore 1988a). IKB retains the NF- $\mathrm{BB}$ in the cytoplasm, inhibits its DNA-binding activity, and couples the activation of NF- $\mathrm{kB}$ to signaling events induced after extra- or intracellular stimulation of cells. Among the physiological activators of NF- $\mathrm{kB}$ are viruses, parasites, $\mathrm{T}$-cell mitogens, cytokines, and bacterial lipopolysaccharide and DNA-damaging agents (for review, see Baeuerle and Baltimore 1990). NF-kB presumably is present in most cell types in an inducible form and in several, such as mature B cells (Sen and Baltimore 1986a), additionally in a constitutive form.

Corresponding author.
The NF- $\mathrm{B}$ protein is composed of at least three distinct subunits. A 48 - to $51-\mathrm{kD}$ protein (referred to as $\mathrm{p} 50$ ) was purified and shown to be responsible for DNA binding (Kawakami et al. 1988; Baeuerle and Baltimore 1989). p50 exists as a homodimer in solution and when complexed with its cognate DNA (Baeuerle and Baltimore 1989). p50 copurifies upon DNA affinity chromatography with an accessory protein of $\sim 65 \mathrm{kD}$ molecular size (p65). Presumably, two molecules of p65 are attached to the p50 dimer forming a heterotetramer. In electrophoretic mobility shift assays (EMSAs), a protein-DNA complex containing the p50 dimer can easily be distinguished by its higher mobility from the protein-DNA complex containing the heterotetramer. In extracts from most cells, the slower migrating complex containing the NF- $\mathrm{B}$ heterotetramer prevails.

The heterotetrameric form of NF-kB binds with a dissociation constant in the range of $10^{-12}$ to $10^{-13} \mathrm{M}$ to the most frequent cognate $\mathrm{\kappa B}$ motif $5^{\prime}$-GGGACTTTCC-3' (Zabel et al. 1991). The pentameric half-sites of this motif appear to interact differently with the protein. The first half-site, A, is highly conserved among all known $\kappa \mathrm{B}$ sites (consensus, $5^{\prime}$-GGGPuN-3') and is bound better than half-site $B$. Half-site $B$ is more degenerate and is fully conserved only in the outermost position. In most cis-acting $\mathrm{kB}$ motifs, not more than 6 nucleotides per decameric site are palindromic. These findings are in some contrast to the notion that p50 binds to DNA as homodimer.

The third subunit of NF- $\mathrm{kB}$ is the inhibitory protein 
IאB (Baeuerle and Baltimore 1988a). The major $\alpha$-form of I $\mathrm{KB}$ was purified and shown to be a $35-$ to $37-\mathrm{kD}$ polypeptide (Ghosh and Baltimore 1990; Zabel and Baeuerle 1990). A minor form, IkB- $\beta$, with an apparent molecular mass of $43 \mathrm{kD}$, appears to be a distinct protein (Zabel and Baeuerle 1990; E. Link and P.A. Baeuerle, unpubl.). IKB is found only associated with the inducible cytoplasmic form of NF- $\mathrm{kB}$, which is apparently composed of one p50, one p65, and one IкB molecule. Release of $I_{\kappa} B$ following protein kinase C-dependent phosphorylation (Shirakawa and Mizel 1989; Ghosh and Baltimore 1990; U. Zabel and P.A. Baeuerle, unpubl.) or deoxycholate (DOC) treatment in vitro (Baeuerle and Baltimore 1988b) allows two p50-p65 heterodimers to combine to the active heterotetramer, which can enter the nucleus (Baeuerle and Baltimore 1988a,b).

In vitro, only the heterotetrameric form of NF- $\mathrm{kB}$ can be dissociated by IKB (Baeuerle and Baltimore 1989) even when bound with high affinity to DNA (Zabel and Baeuerle 1990). In vivo this might happen during a chronic treatment of pre-B cells with phorbol 12-myristate 13-acetate (PMA) (Baeuerle et al. 1988). These observations suggested that IKB requires p65 to inactivate the DNA binding of $\mathrm{p} 50$. The precise role of $\mathrm{p} 65$ in this process, however, remained unclear. A methylation interference analysis using the $\kappa$ enhancer-binding motif showed no influence of p65 on the DNA contacts required by p50 (Baeuerle and Baltimore 1989), but p65 was found to increase the angle and alter the position of DNA bending induced by $\mathrm{p} 50$ (R. Schreck, H. Zorbas, E.-L. Winnacker, and P.A. Baeuerle, in prep.).

In this study we have further investigated the interactions between the three purified NF-KB subunits and found novel functions for p65. Purified p65 could specifically inactivate $I_{\kappa} B$ and induce the formation of an ac- tive heterotetramer from the p50-p65-IкB complex, presumably by complexing occasionally released IкB. These novel activities of p65 are explained best by a receptor function of $\mathrm{p} 65$ for IкB. The $\mathrm{p} 50$ dimer of NF- $\mathrm{kB}$ was found to be inert for binding of $\mathrm{p} 65, \mathrm{I}_{k} \mathrm{~B}$, and the presumptive p65-IкB complex, suggesting that an association of p50 and p65 must occur early during biogenesis of p50. Physiological consequences of the in vitro observations are discussed. We demonstrate further that p65 can alter the DNA-binding specificity of p50 dimers. In the presence of p65, p50 had a strongly decreased affinity for completely palindromic sites but bound with higher affinity to the less symmetric physiological $\mathrm{\kappa B}$ motif than $\mathrm{p} 50$ alone. $\mathrm{p} 50$ dimers could be detected in Jurkat and $70 Z / 3$ pre-B cells by using a completely palindromic binding site as DNA probe in EMSAs. The DNA-binding activity of p50 dimers was not inducible and enriched in the nuclear fraction. It was much less abundant than that of heterotetramers in stimulated cells.

\section{Results \\ p65 cannot associate with the dimerized DNA-binding form of $p 50$}

The NF- $\mathrm{kB}$ that was affinity-purified with the DNA cognate motif 5'-GGGACTTTCC-3' from cytosol of human placenta is exclusively obtained as a complex of p50 and $\mathrm{p} 65$, as is evident from the mobility of the protein-DNA complex in EMSAs (Fig. 1, lane 1). NF- $\mathrm{kB}$ presumably is a heterotetramer in which two $\mathrm{p} 65$ molecules are bound to two p50 molecules (Baeuerle and Baltimore 1989). Active NF-kB, which consists solely of the dimerized
Figure 1. Characterization of NF- $\mathrm{B}$ purified from human placenta. NF- $\mathrm{kB}$, which was affinitypurified from human placenta, was subjected to SDS-polyacrylamide gel electrophoresis (SDSPAGE), followed by excision of $\mathrm{p} 50$ and $\mathrm{p} 65$ from the gel, elution, and renaturation of p50 and p65. The proteins were analyzed in an EMSA, using a ${ }^{32}$ P-labeled double-stranded 30-mer oligonucleotide encompassing the NF- $\mathrm{kB}$-binding site from the $\kappa$ light-chain enhancer (Sen and Baltimore 1986a). (Lanes 1 and 10) Affinity-purified NF-kB; (lanes 2 and 11) p50 renatured in the absence of p65; (lanes 3 and 4) p65 renatured in the absence of p50; (lane 5) combined renaturation (star) of p50 and p65; (lanes 6-9) addition of increasing amounts of renatured p65 to p50; (lanes 12 and 13) test of a lower molecular weight control fraction for DNA-binding activity; (lanes 14-17) addition of control fraction to p50. Fluorograms of native gels are shown. Numbers at top correspond to microliters. Solid arrowheads indicate the position of the protein-DNA complex of heterotetrameric NF- $\mathrm{KB}$; the arrow indicates that of $\mathrm{p} 50$ dimer; the open arrowhead indicates the position of unbound DNA probe.

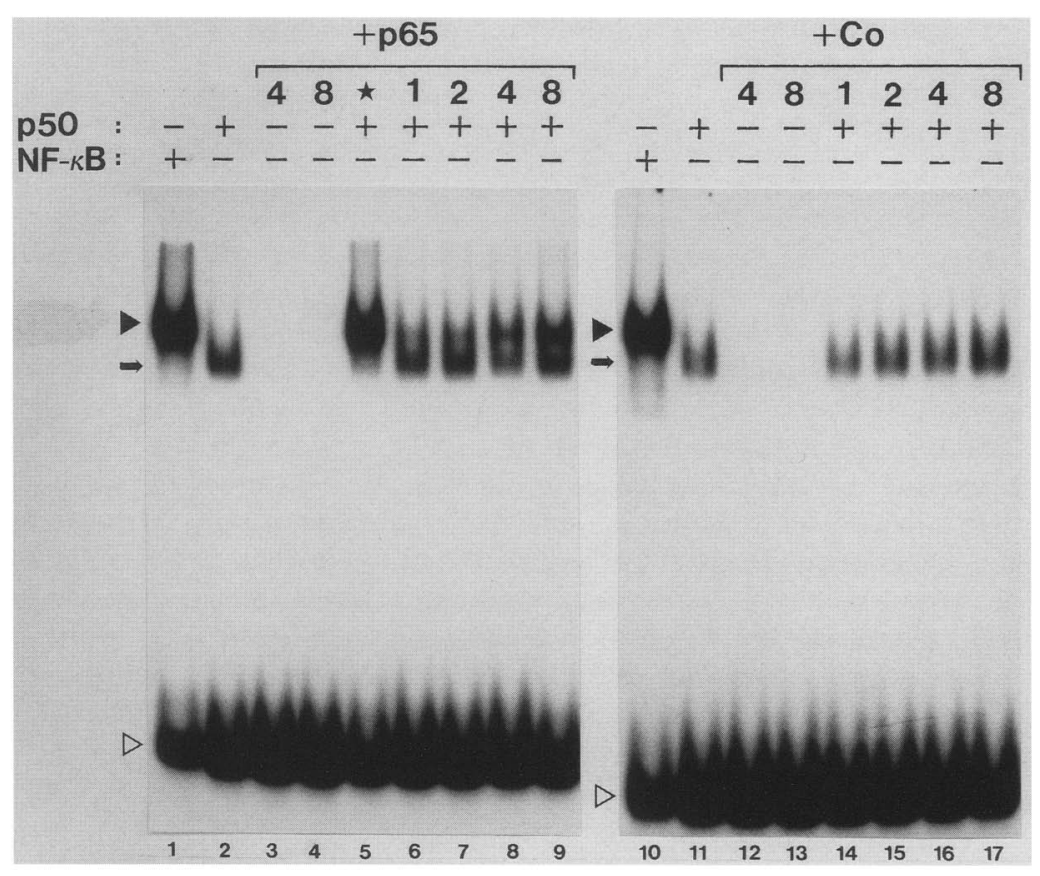


DNA-binding p50 (p50 dimer), can be produced by electrophoretic separation of $\mathrm{p} 50$ from $\mathrm{p} 65$ followed by renaturation of p50 (Fig. 1, lane 2). The p50 dimer not only can be distinguished from the heterotetramer by the increased mobility of its complex with DNA in native gels (Fig. 1) but also by its insensitivity toward the inhibiting activity of IKB (Fig. 2B, lane 2), as was observed earlier with the p50 dimer obtained from HeLa cells (Baeuerle and Baltimore 1989|. No DNA-binding activity is found associated with gel-purified p65, at least none with a specificity for the $\mathrm{\kappa B}$ motif (Fig. 1, lanes 3 and 4). If equal amounts of p50 and p65 are pooled and subjected to a renaturation protocol, the heterotetramer can be fully reconstituted (Fig. 1, lane 5). As noted earlier, the addition of p65 to a fraction containing (partially) renatured p50 gave raise to the heterotetramer (Fig. 1, lanes 6-9); however, less heterotetramer was obtained than by corenaturing p50 and p65 (Fig. 1, cf. lanes 5, 6, and 9). The amount of p50 dimer was not significantly reduced after addition of p65, suggesting that it was not involved in assembling the heterotetramer. These observations suggest that p65 cannot combine with p50, which has already adopted a dimerized DNA-binding form. Presumably, only p50, which is in a yet unfolded or monomeric form, can bind p65 (see Fig. 3, reactions 1 and 2). A control fraction from a molecular weight region adjacent to the one containing p 65 could not reconstitute the heterotetramer (Fig. 1, lanes 14-17).

\section{Purified p65 can neutralize the inhibiting activity of $I \kappa B$}

Because I $\kappa$ B can only inactivate the heterotetramer, but not the p50 dimer of NF- $\mathrm{kB}$, it was assumed that the p65 contained in the heterotetramer is required for the inactivation by IкB (Baeuerle and Baltimore 1989; Zabel and Baeuerle 1990). However, it was unclear from these studies whether p65 modifies p50 such that the latter can directly interact with IкB or whether p65 serves as a receptor for the $I_{k} B$ protein. To distinguish between these possibilities, we tested the ability of isolated p 65 to neutralize the inhibiting activity of the purified 37-kD $\alpha$-form of IкB (Zabel and Baeuerle 1990). The amounts of the various protein subunits of NF- $\mathrm{kB}$ were determined, as described in Materials and methods. An amount of IkB was used that was in a stoichiometric relation to the heterotetramer, as is evident from the almost complete inhibition of the DNA-binding activity (Fig. 2A, lanes 2, 7, and 12). If the IкB was preincubated with increasing amounts of $\mathrm{p} 65$, an increasing amount of heterotetramer could escape the inhibition by $I_{\kappa} B$ (Fig. 2A, lanes 3-5). The inhibitor was not affected in its activity by a control fraction from the SDS gel, which was treated identically to that containing p65 (Fig. 2A, lanes $8-10$ ). Preincubation of I $k B$ with a fraction containing p50 showed only an increasing signal corresponding to that of the p50 dimer but could not inactivate IкB, as would have been reflected by the appearance
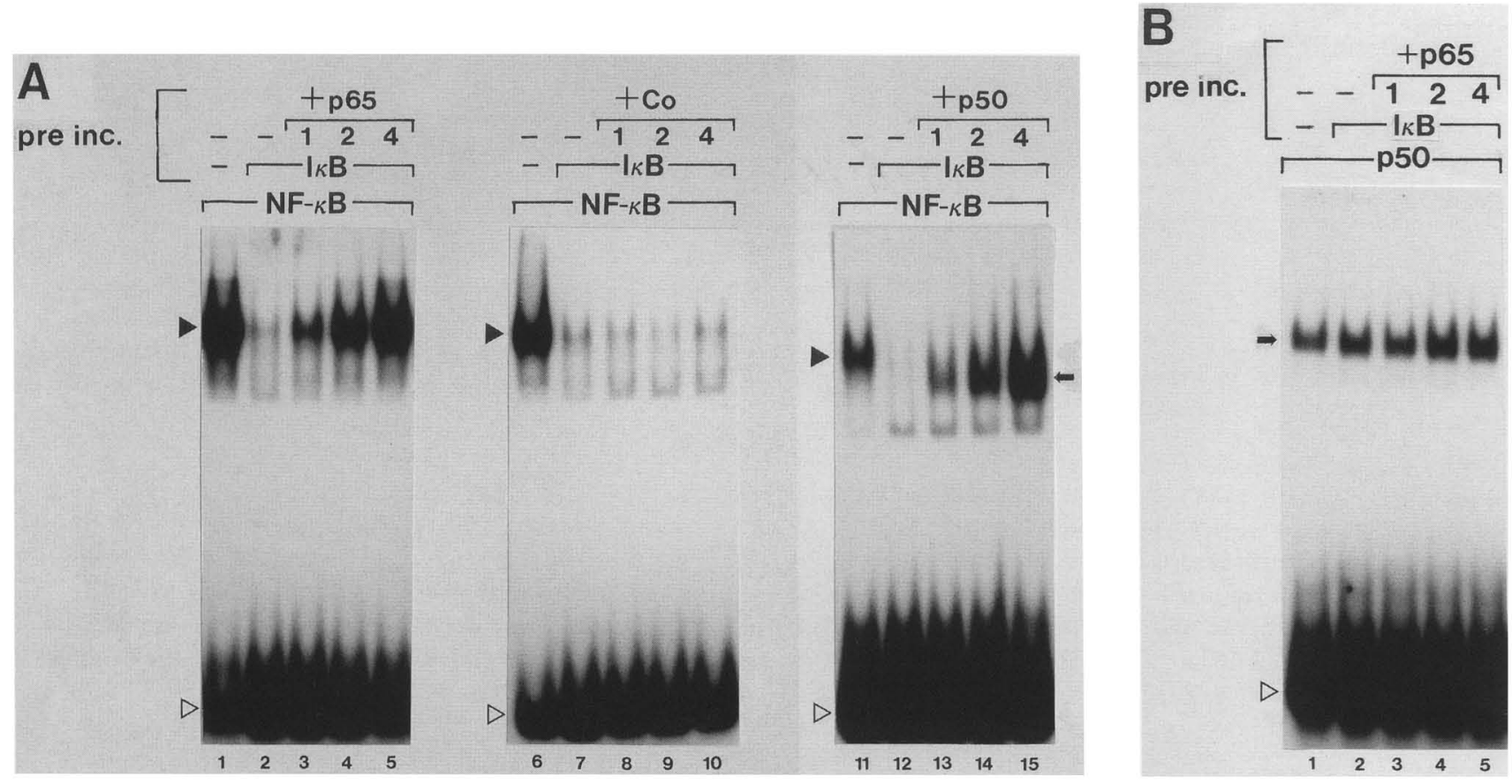

Figure 2. The effect of $\mathrm{p} 65$ on the inhibiting activity of $\mathrm{I}_{\kappa} \mathrm{B}-\alpha$. The analysis was performed by EMSA (see legend to Fig. 1$)$. (A) Purified heterotetrameric NF-kB (lanes 1,6,11) was reacted with an amount of purified IKB ( $\alpha$-form) that gave almost complete inhibition of DNA binding (lanes 2,7,12). The same amount of $\mathrm{I} K \mathrm{~B}$ was incubated for $10 \mathrm{~min}$ at room temperature with increasing amounts of p65 (lanes 3-5; in $\mu \mathrm{l}$ ), a control molecular size fraction (Co, lanes 8-10), or p50 (lanes 13-15) prior to addition to NF- $\mathrm{kB}$. On a shorter exposure of lane 15, a single band corresponding to that of the p50 dimer was seen. $(B)$ Incubation of p50 dimer (lane 1 ) with IkB alone (lane 2) or IкB preincubated with increasing amounts of p65 (lanes 3-5). Fluorograms of native gels are shown. The solid arrowhead indicates the position of the protein-DNA complex of heterotetrameric NF- $\mathrm{kB}$, the arrow indicates that of p50 dimer, and the open arrowhead indicates the position of unbound DNA probe. 
Urban and Baeuerle

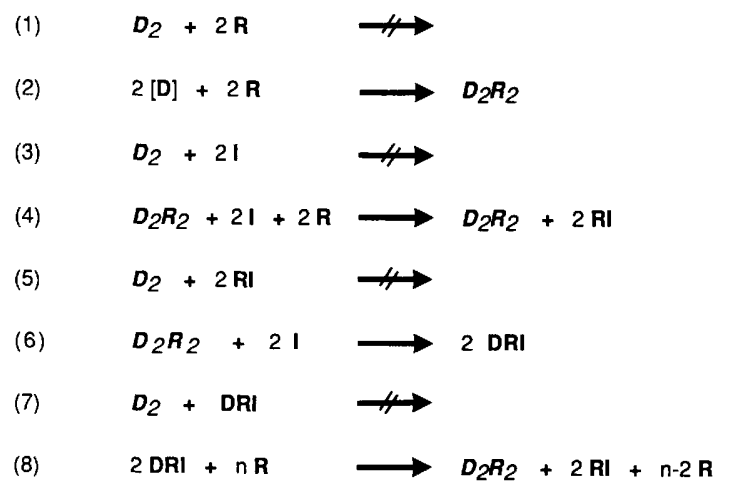

Figure 3. Summary of the possible and impossible interactions between subunits of NF-кB and their various complexes. The stoichiometries of $D_{2} R_{2}, D_{2}$, and DRI complexes were evident from other studies (Baeuerle and Baltimore 1989; Zabel and Baeuerle 1990) and that of RI was not yet determined. Also R and $I$ are likely to exist as homodimers in solution (Zabel and Baeuerle 1990; M.B. Urban and P.A. Baeuerle, upubl.). (D) p50, DNA-binding subunit; (R) p65, receptor or regulatory subunit; (I) IкB, inhibitory subunit; $\left(D_{2}\right)$ p50 dimer (DNA binding); $\left(D_{2} R_{2}\right)$ heterotetramer (DNA binding); (DRI) inducible form of NF- $\mathrm{KB}$ (not DNA binding).

of the heterotetramer (Fig. 2A, lanes 13-15). Because the p50 dimer was not inhibited by IкB (Baeuerle and Baltimore 1989; Fig. 2B, lane 2) and could not inactivate IкB (Fig. 2A, lanes 13-15), the two molecules apparently cannot interact directly with each other (see Fig. 3, reaction 3). The specificity and dose dependence of the inhibition of $\mathrm{I}_{\kappa} \mathrm{B}$ by $\mathrm{p} 65$ are consistent with the formation of a complex between $\mathrm{p} 65$ and $\mathrm{I}_{\kappa} \mathrm{B}$, which prevented the IkB from interacting with the p65 contained in the DNA-binding heterotetramer (see Fig. 3, reaction 4). The presumptive complex of p65 and IкB did not react with the p50 dimer and cause inhibition of DNA binding (Fig. $2 \mathrm{~B}$, lanes $3-5$ ), suggesting that p65 is unable to associate with dimerized p50 even in the presence of $I_{K} B$ (Fig. 2B; see Fig. 3, reaction 5).

\section{Activation of the p50-p65-I $B$ complex by excess $p 65$}

The inducible form of NF- $\mathrm{BB}$ is thought to be a heterotrimer composed of one p50, one p65, and one IkB molecule (Zabel and Baeuerle 1990). This form was reconstituted by dissociating the DNA-binding heterotetramer (Fig. 4, lane 1) with purified IкB- $\alpha$ (lane 2) resulting in $\sim 90 \%$ conversion (lane 9 ; see Fig. 3 , reaction 6 ). The effect of excess purified p65 on this inactivated form of NF- $\mathrm{kB}$ was tested. The addition of increasing amounts of p65 caused a dose-dependent activation of the p50-p65-IKB complex, as seen by the appearance of the heterotetramer (Fig. 4, lanes 3-5). p50, as a control, could not increase the amount of heterotetramer, suggesting that it could not react with the inducible form of NF-KB (Fig. 4, lanes 6 and 7; see Fig. 3, reaction 7). The activation of NF-kB by p 65 was better than that achieved by a treatment with DOC /data not shown; Baeuerle and Baltimore 1988a) and, in fact, was the most efficient activation of a p50-p65-IКB complex that we ever ob-

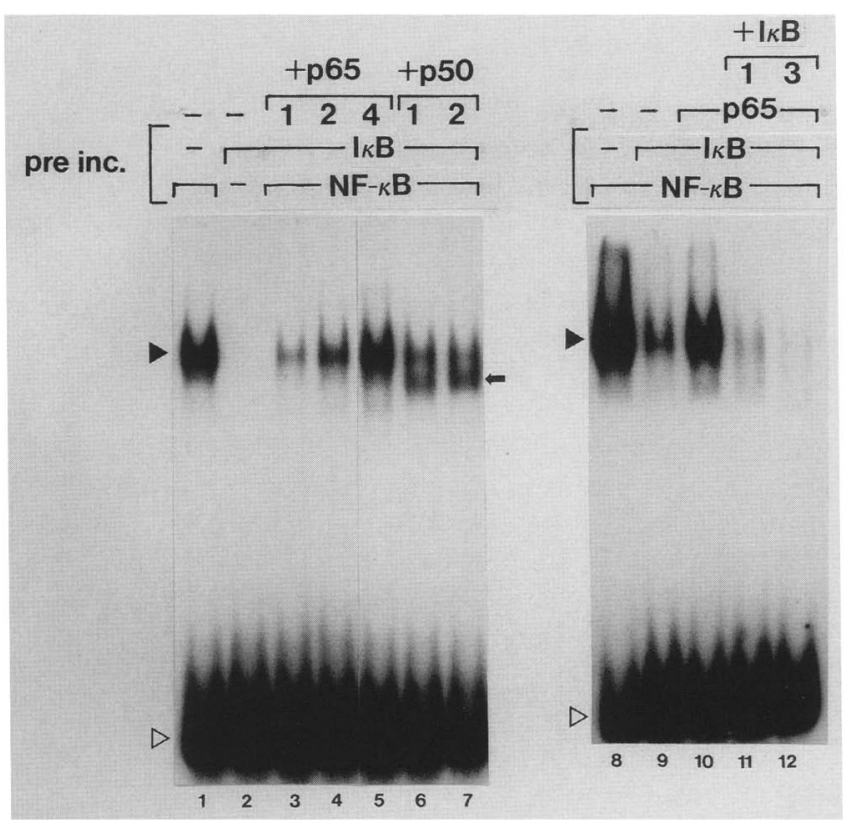

Figure 4. The effect of $\mathrm{p} 65$ on the inducible form of NF-кB. The analysis was performed by EMSA. (Left) Purified heterotetrameric NF- $\kappa B$ (lane 1) and purified IкB- $\alpha$ (lane 2) were combined to yield the inactivated form of NF- $\mathrm{B}$ (p50-p65-IкB complex) (lane 9). Increasing amounts (in $\mu$ l) of gel-purified p65 (lanes 3-5) or p50 (lanes 6 and 7) were added and incubated for $10 \mathrm{~min}$ prior to the addition of a DNA-binding mix. The same result was obtained if the DNA-binding mix was immediately added (data not shown). (Right) To a reaction in which NF-kB was partially activated by p 65 (lane 10 ; corresponding to lane 4), two concentrations of IKB were added (lanes 11 and 12). Fluorograms of native gels are shown. Solid arrowheads indicate the position of the protein-DNA complex of heterotetrameric $\mathrm{NF}-\mathrm{\kappa B}$, the arrow indicates that of the p50 dimer, and the open arrowhead indicates the position of unbound DNA probe.

served in vitro. If purified I $\mathrm{kB}$ was titrated to NF- $\mathrm{B}$, which was partially activated by p65 (Fig. 4, lane 10), a dose-dependent inhibition of the heterotetramer was seen (lanes 11 and 12). This indicated that the p65 fraction did not contain an IкB-degrading activity but could stoichiometrically complex IкB. The activation of the p50-p65-IкB complex by excess p65 was presumably the result of absorbing to free p 65 the $I \kappa B$, which is released from the inactive complex due to its inherent off rate (see Fig. 3, reaction 8 ). The activation by p65 was completed within $15 \mathrm{~min}$, the time required to monitor the activation process by a DNA-binding reaction in EMSAs (data not shown). This suggests that the half-life of a complex between IкB and p65 was shorter than 15 $\min$.

p65 increases the binding affinity of p50 for the $\kappa B$ motif 5'-GGGACTTTCC-3'

We recently determined a dissociation constant of $2.7 \times 10^{-12} \mathrm{M}$ for the complex of the heterotetramer of NF- $\kappa B$ with the DNA recognition site 5'GGGACTTTCC-3' (Zabel et al. 1990). Here, we have 
compared the affinities of the heterotetramer and p50 dimer for the same $\kappa$ В motif. In contrast to the earlier study that used an affinity eluate, the heterotetramer was prepared here by corenaturing gel-purified p50 and gel-purified p65 (see Fig. 1, lane 5). The p50 dimer was obtained by renaturing p50 on its own (lane 2). A radioactive DNA probe of a known high specific activity was used (Zabel et al. 1991), and the amounts of bound and free DNA were determined using EMSAs (Meisterernst et al. 1988). The concentrations of active DNA-binding proteins were calculated from a titration using saturating amounts of the DNA probe.

A dissociation constant of $4 \times 10^{-13} \mathrm{M}$ was obtained for the heterotetramer (Fig. 5). This number was lower than that determined earlier for the affinity-purified heterotetramer, which was not reconstituted from gel-purified protein subunits and contained minor protein components. Substances that interfered with DNA binding were presumably removed upon gel purification of the protein subunits. If $\mathrm{p} 65$ was not bound to $\mathrm{p} 50$, the affinity of p50 for the 5'-GGGACTTTCC-3' sequence dropped twofold. A dissociation constant of only $9 \times 10^{-13} \mathrm{M}$ was obtained (Fig. 5), indicating that p65 can increase the affinity of the p50 dimer for the $\mathrm{kB}$ motif. In the following, we explored the possibility that

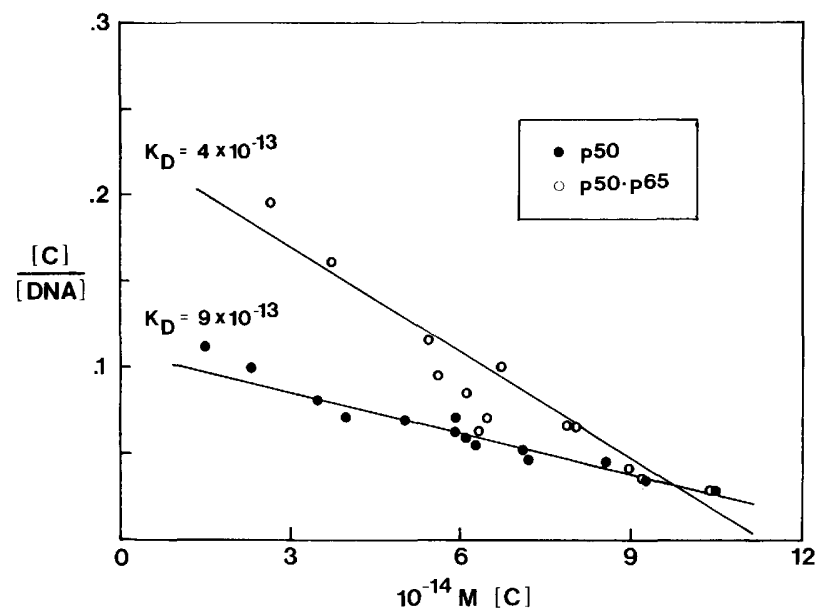

Figure 5. Determination of dissociation constants of NF- $\mathrm{kB}-$ DNA complexes. Gel-purified p50 and a heterotetramer that was obtained by combined renaturation of gel-purified p50 and p65 were used. The concentration of active proteins was determined by titration with saturating amounts of a DNA probe of known specific activity in EMSA. Equal amounts of DNAbinding activity were used for the titration. The DNA probe was a double-stranded oligonucleotide encompassing NF-кBbinding site $5^{\prime}$-GGGACTTTCC-3' from the mouse $\kappa$ lightchain enhancer. It allows fill in of $20^{32} \mathrm{P}$-labeled nucleotides by the Klenow polymerase reaction and was incubated with the proteins in the absence of nonspecific competitor DNA /described in Zabel et al. 1991). EMSAs were used to separate free from bound DNA (Meisterernst et al. 1988), and the radioactivity in the position of bound and free DNA was determined by liquid scintillation counting, followed by correcting numbers for counting efficiency and radioactive decay. [C] Concentration of protein-DNA complex; [DNA] concentration of unbound DNA. the affinity differences reflect an altered binding specificity of $\mathrm{p} 50$ due to bound $\mathrm{p} 65$.

\section{p65 can alter the DNA-binding specificity of p50}

A comparison of all known physiologically active NF- $\mathrm{kB}$-binding sites revealed that most are of rather low symmetry and consist of pentameric half-sites with distinct degrees of sequence conservation (Zabel et al. 1991). This was surprising because p50 forms a homodimer (Baeuerle and Baltimore 1989) and, therefore, should be able to bind to or even require highly palindromic sites. We have tested whether both the heterotetramer and $\mathrm{p} 50$ dimer of NF- $\mathrm{KB}$ can recognize artificial $\kappa \mathrm{B}$ motifs of perfect symmetry, which were derived by duplicating the two pentameric half-sites /referred to as $\mathrm{A}$ and $\mathrm{B} /$ in the most frequent $\mathrm{\kappa B}$ motif $5^{\prime}$-GGGACTTTCC- $3^{\prime}$ into motifs with the sequence $5^{\prime}$-GGGACGTCCC-3' (AA) and 5'-GGAAA-TTTCC-3' (BB). Three double-stranded oligonucleotides containing single copies of these sites within identical flanking sequences were compared for their ability to compete for binding of the two NF-kB forms to a labeled oligonucleotide with the AB site (Fig. 6). Molar excesses of competitors of 2.5-, 25-, and 250-fold over the ${ }^{32}$ P-labeled oligonucleotide were tested, and the titration (Fig. 6B) was performed in duplicate. The p50 dimer could recognize all three sites with similar, but clearly distinguishable, affinities (Fig. 6A, lanes 2-10; Fig. 6B, left). The efficient competition by the palindromic sites $A A$ and $B B$ is indeed consistent with p50 binding as homodimer. The significant difference between the $\mathrm{AA}$ and $\mathrm{BB}$ sites to compete for binding to $A B$ supports the idea that the more highly conserved half-site $\mathrm{A}$ is bound better by p50 than the degenerate half-site $B$, as was apparent in a competition experiment using isolated single half-sites within identical flanking sequences (Zabel et al. 1991). Homologous competition with the $\mathrm{AB}$ site gave an intermediate profile (Fig. 6B, left). An unrelated double-stranded oligonucleotide could not compete for binding (Fig. 6, lanes $11-13$ ). In the presence of $\mathrm{p} 65, \mathrm{p} 50$ was unable to bind the two palindromic sites $\mathrm{AA}$ and $\mathrm{BB}$ with high affinity (Fig. 6A, lanes 18-23; Fig. 6B, right). A 10- to 20-fold higher amount of these oligonucleotides was required to compete for binding of the heterotetramer to the $\mathrm{AB}$ site than was required by the p50 dimer. The unrelated oligonucleotide could not compete for binding (Fig. 6, lanes 24-26). The competition experiments suggest that p65 can alter the DNA-binding specificity of p50 such that completely symmetric sites are no longer recognized with high affinity. More asymmetric sites, which are found as cis-acting elements in many genes (see Lenardo and Baeuerle 1989; Baeuerle and Baltimore 1990), appear to be the preferred target sequences for the heterotetramer.

\section{A completely palindromic $\kappa B$ motif detects p50 as a constitutive nuclear DNA-binding activity}

The data shown in Figure 6 demonstrate that the DNAbinding activity of the p50 dimer can be distinguished 
Figure 6. Comparison of the DNAbinding specificity of $\mathrm{p} 50$ dimer and heterotetrameric NF-кB. (A) Gel-purified p50 (lanes 1-13) and affinity-purified heterotetramer (p50-p65; lanes 14-26) were used in EMSAs with $\sim 0.1 \mathrm{ng}$ of a $32 \mathrm{P}$-labeled 30-mer oligonucleotide containing the NF-кB-binding site GGGACTTTCC /AB site). A competition analysis is shown in which no competitor (lanes 1 and 14) or 2.5-, 25-, and 250-fold molar excesses of unlabeled oligonucleotides /corresponding to $0.25,2.5$, and $25 \mathrm{ng}$ / were added to the DNA-binding reaction. Proteins were added last. (Lanes 2-4 and 15-17) Homologous competition with the $\mathrm{AB}$ site GGGACTTCCC; (lanes 5-7 and 18-20) competition with an oligonucleotide containing the AA site GGGACGTCCC; (lanes 8-10 and 21-23) competition with an oligonucleotide containing the BB site GGAAATTTCC. The three different sites were contained in oligonucleotides of identical length and flanking sequence (for sequence, see Materials and methods). The unrelated DNA fragment used as a nonspecific competitor (unrelated, lanes 11-13 and 24-26) corresponded to a 56-bp sequence upstream from the EcoRI site in the polylinker of the plasmid pKK 223-3 (Pharmacia). Sections of fluorograms are shown containing the protein-DNA complexes (solid arrowheads). (B) Quantitation of the titration experiments. Results from a duplication determination are shown. (E) Unrelated control oligonucleotide; $(0)$ $\mathrm{AB}$ site; $(\triangle) \mathrm{AA}$ site; $(\square) \mathrm{BB}$ site.

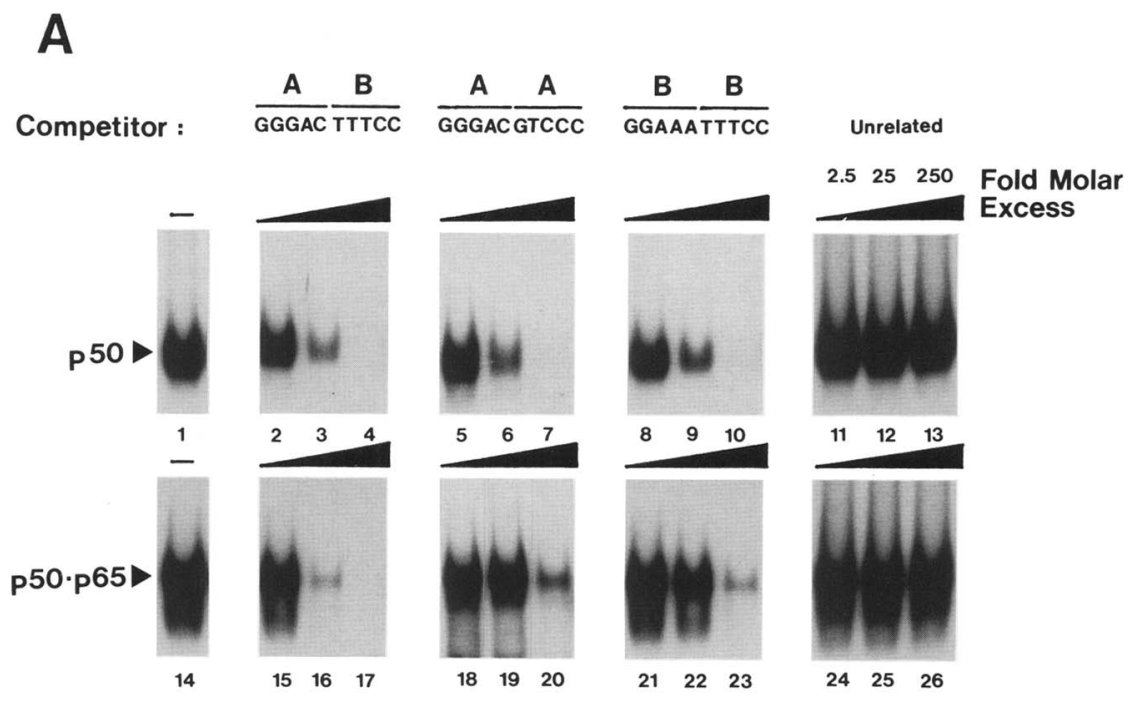

B

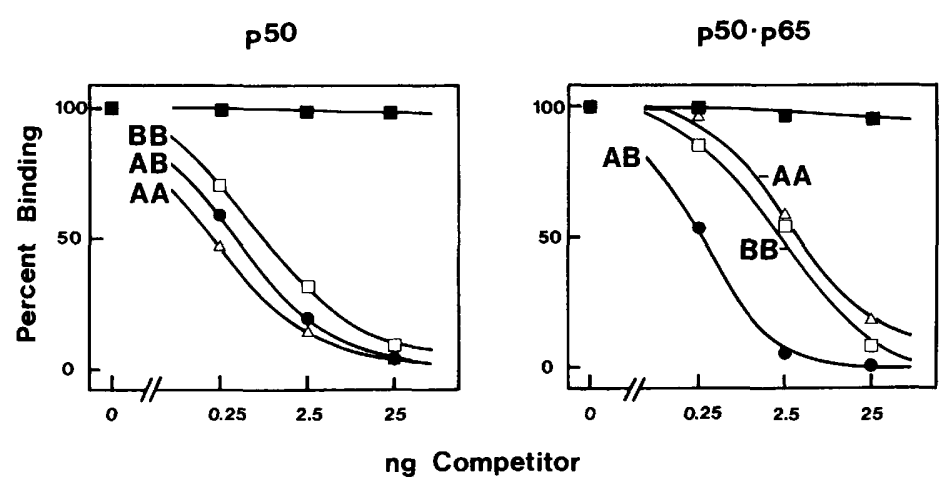

from that of the heterotetramer by its higher affinity for the completely palindromic site AA. We therefore used a ${ }^{32} \mathrm{P}$-labeled AA oligonucleotide in EMSAs to investigate whether the p50 dimer is present in nuclear and cytosolic fractions from Jurkat $T$ cells and $70 Z / 3$ pre-B cells. A protein-DNA complex with the mobility of that obtained with the $\mathrm{p} 50$ dimer was detectable in nuclear extracts from both cell types (Fig. 7A,B, lanes 1) but was not seen in the cytosolic fractions (Fig. 7A,B, lanes 2). Following stimulation of Jurkat cells with PMA/phytohemagglutinin and of $70 Z / 3$ cells with PMA alone, the amount of this complex showed only a weak increase (Fig. 7A,B, lanes 3). The AA oligonucleotide could form a second complex of slower mobility exclusively in the nuclear extracts from induced cells (Fig. 7A,B, lanes 3). This complex corresponded to that of the heterotetramer of NF-kB, as indicated by its comigration with the complex detected by the $A B$ site from the $\kappa$ enhancer and its inducibility upon stimulation of the two cell types (Fig. $7 \mathrm{~A}, \mathrm{~B}$, lanes $5-8)$. As was already evident from the competition experiments (Fig. 6), the newly activated heterotetramer of NF- $\mathrm{kB}$ can bind much better to the $\mathrm{AB}$ than to the AA site (Fig. 7A,B, cf. lanes 3 and 7). In contrast, purified p50 dimer can form similar amounts of complex with the $A A$ and $A B$ site (Fig. $7 \mathrm{C}$, lanes 1 and 2). Also in cell extracts, the complex of the p50 dimer was detectable with the $A B$ site (Fig. 7A,B, cf. lanes 1 and 5), but it was obscured by that of the heterotetramer.

The specificity of the protein-DNA complexes formed with the AA site was tested by competition with a 20-fold molar excess of unlabeled oligonucleotides (Fig. $7 \mathrm{~A}, \mathrm{~B})$. While the complex of the p50 dimer was competed to a similar extent with $\mathrm{AA}$ and $\mathrm{AB}$ sites, the complex of the heterotetramer was competed much more efficiently by the $A B$ than the AA site (Fig. 7A,B, lanes 10 and 11). An unrelated double-stranded oligonucleotide could not compete for binding (lane 12). The slow migrating complexes 1 and 2 were obtained with fractions from both cell types, while complex 3 was only seen in cytoplasmic and nuclear fractions from the T-cell line. All three complexes showed no specificity for the $\kappa B$ motif because their formation was not inhibited by excess amounts of unlabeled specific $\mathrm{AA}$ and $\mathrm{AB}$ oligonucleotides (Fig. 7A,B, lanes 10 and 11 ).

Our results suggest that $\mathrm{p} 50$ dimers occur without attached $\mathrm{p} 65$ as a constitutive, perhaps weakly inducible, nuclear DNA-binding protein in both cell types investigated. Because of the very low abundance of p50 dimers compared to heterotetramers in stimulated cells, a physiological significance of p50 dimers is doubtful, at least 
A

B

JURKAT

$70 Z / 3$

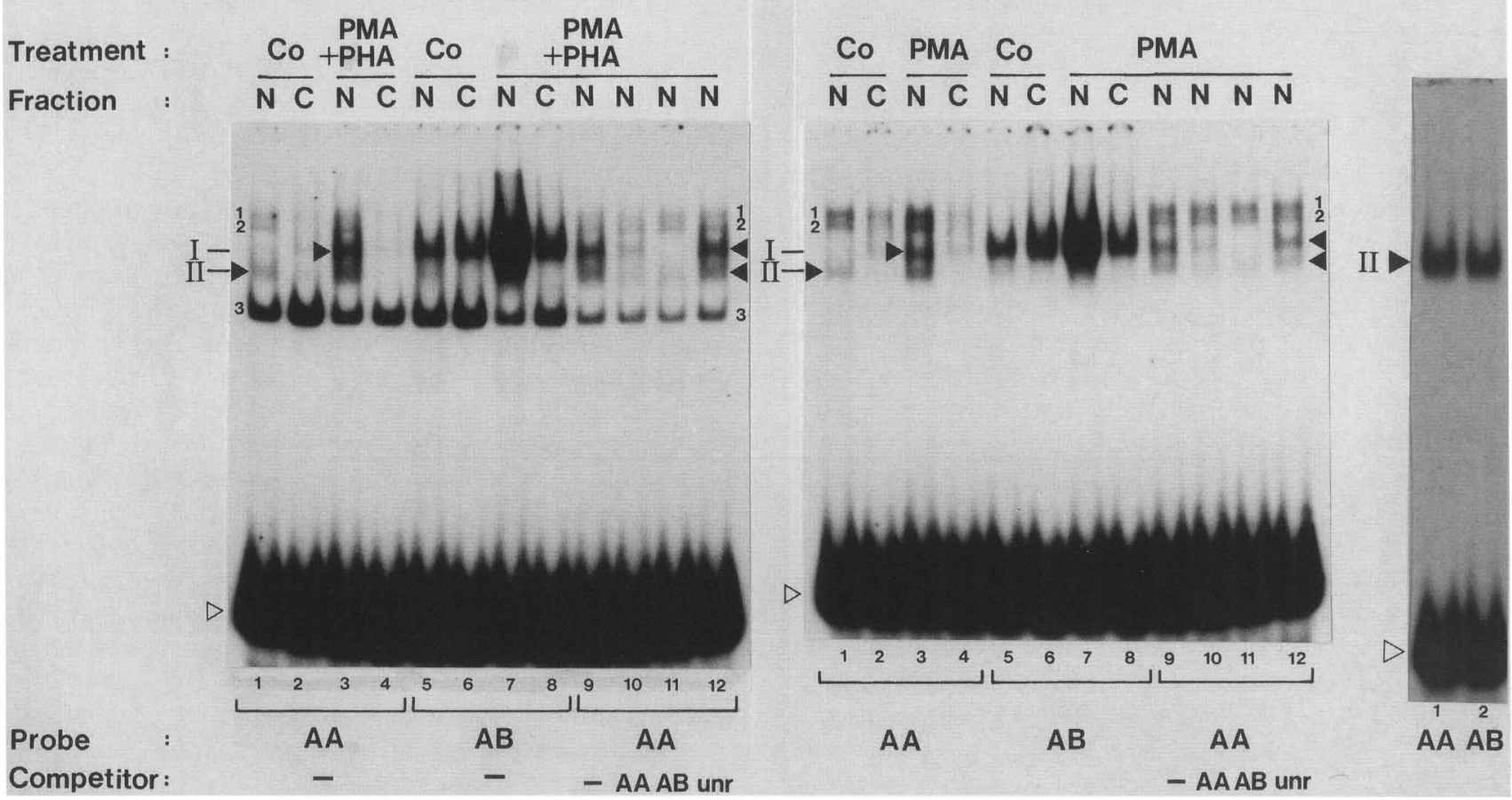

Figure 7. Detection of $\mathrm{p} 50$ dimers in nuclear extracts from cells. Nuclear extracts $(\mathrm{N})$ and cytosolic fractions $(\mathrm{C})$ were prepared from Jurkat $T$ cells $|A|$ or $70 Z / 3$ pre-B cells $(B)$, as described (Baeuerle and Baltimore 1988b). Cells were left untreated (Co) or stimulated for $30 \mathrm{~min}$ with $50 \mathrm{ng} / \mathrm{ml}$ PMA $(70 \mathrm{Z} / 3$ ) or for $4 \mathrm{hr}$ with a combination of $50 \mathrm{ng} / \mathrm{ml}$ PMA plus $5 \mu \mathrm{g} / \mathrm{ml}$ phytohemagglutinin (PHA) (Jurkat). Equal portions of cell extracts containing $2 \mu \mathrm{g}(\mathrm{N})$ or $8 \mu \mathrm{g}(\mathrm{C})$ of protein were used in EMSAs with $2 \mu \mathrm{g}$ of poly[d(I-C)]. The ${ }^{32} \mathrm{P}-\mathrm{labeled}$ oligonucleotides contained either the AA site (lanes 1-4 and 9-12) or the AB site (lanes 5-8) and had the same specific activity. In lanes 10-12, binding to the labeled AA site was competed with a 20 -fold molar excess of cold oligonucleotides with the AA site (lane 10 , the $\mathrm{AB}$ site (lane 11), or an unrelated DNA fragment (lane 12; see legend to Fig. 5). (I) Heterotetrameric NF- $\mathrm{kB}$; (II) p50 dimer; (1-3) nonspecific DNA-binding activities. Fluorograms of native gels are shown. Solid arrowheads indicate the positions of the proteinDNA complexes of the two NF- $\mathrm{BB}$ forms. The open arrowhead indicates the position of unbound DNA probes. $(C)$ Binding of equal amounts of gel-purified p50 to ${ }^{32} \mathrm{P}$-labeled oligonucleotides containing the AA (lane 1) or AB site (lane 2).

in the investigated cell lines. An elevated amount of p50 dimer is apparently present in macrophages (Collart et al. 1990). It cannot be excluded that under certain expermental conditions or in certain cell types p50 dimers are artifactually created upon fractionation of cells. For instance, selective degradation of p65 in the cytoplasmic fraction could create p50 dimers that can bind to DNA contained in damaged nuclei. Alternatively, the induced nuclear NF- $\mathrm{kB}$ could be degraded to give p50 dimers. This could provide a possible explanation for the slight increase of p50 dimers upon stimulation of cells (Fig. 7A and $\mathrm{B}$, lanes 1 and 3 ).

\section{Discussion}

Using purified components, we have investigated in this study interactions between the three subunits of the NF- $k B$ transcription factor: the DNA-binding p50, the inhibitory $I_{\kappa} B$, and the p65 subunit. No direct interactions between the IKB and p50 was evident, but all data obtained argue for a receptor function of p 65 for IкB: the requirement of p65 for inhibition by IKB (Baeuerle and Baltimore 1989; Zabel and Baeuerle 1990|, the neutralization of $\mathrm{I} \kappa \mathrm{B}$ by $\mathrm{p} 65$, and the activation of the $\mathrm{p} 50-\mathrm{p} 65-\mathrm{I} \kappa \mathrm{B}$ complex by excess $\mathrm{p} 65$. Because the interaction between $p 65$ and I $k B$ is reversible, has a high turnover as suggested by the activation of NF- $\mathrm{kB}$ during inhibition of protein synthesis (Sen and Baltimore 1986b), and determines the state of activity of NF- $\mathrm{kB}$, the comparison with a receptor-ligand interaction appears justified. As a receptor for $\mathrm{I} k \mathrm{~B}, \mathrm{p} 65$ can control whether $\mathrm{p} 50$ is retained in the cytoplasm and repressed in its DNAbinding activity (Baeuerle and Baltimore 1988b) and whether the heterotetramer is reinactivated by I $\mathbf{B}$ (Zabel and Baeuerle 1990). The inducibility and subcellular localization of NF- $\mathrm{KB}$ is thus not only dependent on IкB but also on $\mathrm{p} 65$.

The association of p65 with p50 appears to be strictly controlled. p65 cannot associate with p50, which is already in a DNA-binding dimerized form and is thus not able to subject a p50 dimer to the regulation by IкB. Association of p50 and p65 must therefore occur early 
during the biosynthesis of p50 while the protein is not yet folded or dimerized. At this stage, the availability of p65 would allow to control whether p50 becomes an IkBor p65-insensitive and thus constitutive and nuclear DNA-binding protein or resides in an inducible form in the cytoplasm. Whereas limiting amounts of p65 should increase the amount of p50 dimers, only equimolar amounts or an excess of p65 can assure quantitative formation of inducible NF-кB. As shown by our experiments, an excess of p65 in the absence of free IкB can activate the $\mathrm{p} 50-\mathrm{p} 65-\mathrm{I}_{\kappa} \mathrm{B}$ complex. Hence, the availability of $I_{\kappa} B$ and the ratio of $I_{\kappa} B$ to p 65 also appear to be crucial for converting p50 into an inducible form. It is even possible that in vivo I $\mathrm{B}$ and p 65 occur in complex with each other. This idea is supported by the observation that the activities of $I \kappa B$ and p 65 are not detectable in cytoplasm (Baeuerle and Baltimore 1988b, 1989). The biosynthesis of the heterotetramer can then result only from an activation reaction: First, the presumptive p65IкB complex associates with monomeric p50; second, I $\mathrm{K}$ dissociates from p50-p65-IкB upon stimulation of cells; finally, two p50-p65 dimers assemble to form the heterotetramer. Equimolar ratios of p65 and $I_{\kappa} B$ in the cell could be achieved by stabilizing an otherwise labile protein in complex with the other one. In B cells, which have constitutively elevated levels of the active heterotetramer in the nucleus (Sen and Baltimore 1986a) but also p50-p65-IкB in the cytoplasm (Baeuerle et al. 1988), the balance between p65 and IKB is presumably perturbed. A decrease in $I_{k} B$, as well as an increase in p65 or both, could contribute to the constitutive activity of the heterotetramer.

An interesting possibility is that p65 also serves in vivo as an activator protein for NF-кB. If the p65-IкB complex is in excess over the p50-p65-I $\mathrm{kB}$ complex, the phosphorylation of IкB by protein kinase C (Ghosh and Baltimore 1990; U. Zabel and P.A. Baeuerle, unpubl.) would also release free p65 that could activate all p50-p65-IKB not yet reached by the membrane-associated protein kinase. In this situation, p65 would function as a messenger between the protein kinase and the p50-p65-IkB complex.

Not only can p65 influence the activity of $I_{\kappa} B$, but it also can influence that of its other ligand, the DNAbinding p50 dimer. A first indication was the finding that the $\mathrm{p} 50$ dimer with bound p65 can bind to the most common $\mathrm{kB}$ motif GGGACTTTCC, two times stronger than the p50 dimer alone. DNA-binding experiments for which the half-sites of this low-symmetry motif were duplicated to yield completely palindromic motifs revealed that the DNA-binding specificity of p50 is significantly influenced by $\mathrm{p} 65$. Only the $\mathrm{p} 50$ dimer could bind with high affinity to the artificial palindromic motifs, whereas the heterotetramer preferred the physiological site. An asymmetry-inducing effect of p65 on p50 was also evident from a recent study showing that NF- $\mathrm{kB}$ induces bending of DNA (R. Schreck et al., in prep.). The position of the bending center induced by the p50 dimer was located in the center of the $\kappa B$ motif, whereas in the presence of $\mathrm{p} 65$, the center of DNA bending was shifted to the $3^{\prime}$ end of the site and the estimated bending angle almost doubled.

One model that would explain the influence of p65 on the DNA binding of p50, as well as the incapability of p50 dimers to bind p65, implies that p50 can either homodimerize or bind a p65 molecule. The binding sites for p50 and p 65 on the p50 molecule could be identical or so close together that they allow only mutually exclusive binding. In the absence of p65, only p50 dimers will form. If p65 is bound in an early stage of p50 biogenesis, the $\mathrm{p} 50$ homodimerization domain becomes masked by p65. However, no dimerization domain would then be left for p50 to assemble an active heterotetramer. It is possible that an alternative domain is provided by $\mathrm{p} 65$, as supported by gel filtration experiments in which purified p65 eluted with the size of a dimer (M.B. Urban and P.A. Baeuerle, unpubl.). In our model, p65 would bridge two unattached or weakly associated p50 molecules. The altered constellation of the two p50 molecules to each other in such a complex could explain the altered DNA-binding specificity and the modification of the DNA bending in the presence of p65. Inactivation of the heterotetramer would simply require dissociation of the presumptive p65-p65 contact by IкB.

The preference of the heterotetramer for binding sites with distinct half-sites and its asymmetric bending of the $\kappa B$ motif would be consistent with a model in which both p50 and p65 contact the cognate DNA in a heterodimeric form. However, we consider this possibility unlikely because UV cross-linking experiments with the heterotetramer demonstrated only covalent linkage of a $50-\mathrm{kD}$ protein to DNA (Kawakami et al. 1988; Collart et al. 1990).

The p50 dimer can bind $\mathrm{\kappa B}$ motifs with high affinity but also recognizes completely palindromic motifs for which the heterotetramer has a low affinity. One highly palindromic site to which the heterotetramer binds with high affinity is the A enhancer from the major histocompatibility complex (MHC) class I gene $\mathrm{H}-2 \mathrm{~K}^{\mathrm{b}}\left(5^{\prime}-\right.$ GGGGATTCCCC-3'; Israel et al. 1989). Methylation interference analysis, however, suggested that the NF- $\mathrm{B}$ heterotetramer prefers to interact in the undecameric palindrome with the decameric motif that shows the lower degree of symmetry (5'-GGGATTCCCC-3'; Baldwin and Sharp 1988). Other factors binding to the palindrome are KBF1 and H2TF1, which prefer a more symmetric contact with the palindrome (Baldwin and Sharp 1988; Israel et al. 1989|. At least one of these factors, KBF1, is indistinguishable from the p50 dimer of $\mathrm{NF}-\mathrm{kB}$ (Kieran et al. 1990). This is suggested by the characteristics of cDNA clones encoding KBF1, the association of KBF1 with purified p65, and by the DNA-binding specificity, immunoreactivity, and partial amino acid sequence of p50, which is identical to that of KBF1. The physiological role of the p50 dimer (KBF1) is unknown. Future studies have to investigate whether a p50 dimer is capable of initiating transcription on its own or whether $\mathrm{p} 65$ has an additional function in providing $\mathrm{p} 50$ with a transcription activation domain. In the latter case, p50 dimers could act as transcriptional repressors 
that, when present in excess over the heterotetramer, can occupy binding sites for trans-activating heterotetramers.

\section{Materials and methods}

\section{Oligonucleotides}

Six 26-mer oligonucleotides were synthesized by the phosphoroamidite method on an Applied Biosystems Synthesizer 310A and purified on OPC cartridges (Applied Biosystems) as described by the manufacturer. The three double-stranded 30-mer oligonucleotides obtained by annealing had SalI and HindIII linker sites. Labeling was performed by the Klenow polymerase reaction using $[\alpha-32 \mathrm{P}] \mathrm{dCTP}$ (Amersham, $3000 \mathrm{Ci} / \mathrm{mmole}$ ) and the three other dNTPs in unlabeled form. The sequences were the following:

$\mathrm{AB}$ site oligonucleotide (mouse $\kappa$ light-chain enhancer motif)

\section{5'-AGCTTCAGAGGGGACTTTCCGAGAGG-3'} 3'-AGTCTCCCCTGAAAGGCTCTCCAGCT-5'

AA site oligonucleotide

\section{5'-AGCTTCAGAGGGGACGTCCCGAGAGG-3' 3'-AGTCTCCCCTGCAGGGCTCTCCAGCT-5'}

$\mathrm{BB}$ site oligonucleotide

\section{5'-AGCTTCAGAGGAAATTTCCGAGAGG-3' 3'-AGTCTCCTTTAAAGGCTCTCCAGCT-5'}

\section{Purification and renaturation of proteins}

The purification of NF- $\mathrm{BB}$ from human placenta is described in Zabel et al. (1991), and that of IкB- $\alpha$ is described in Zabel and Baeuerle (1990). The isolation of p50 and p 65 from affinity-purified NF- $\mathrm{B}$ by SDS-gel electrophoresis and subsequent renaturation is described in Baeuerle and Baltimore (1989). A novel modification of the protocol was as follows. To remove residual SDS from the gel eluate more efficiently, the protein pellet obtained after acetone precipitation was dissolved in a small volume of buffer $\mathrm{D}(+)$ (Baeuerle and Baltimore 1989), followed by a second precipitation with $80 \%$ acetone.

\section{Determination of protein concentrations}

The amounts of the two DNA-binding forms of NF- $\mathrm{kB}$ were calculated from the amount of protein-DNA complex, which was formed in EMSAs with a DNA probe of known specific activity under saturating concentrations of DNA. This was the only means to accurately determine the small amounts of proteins used in this study and had the advantage of measuring only protein that was active in DNA binding.

The amount of p 65 was estimated as follows. Because p50 and p65 occur in the heterotetramer in stoichiometric amounts, it was assumed that in equal volumes of SDS gel eluates obtained from electrophoresis of the heterotetramer equal amounts of the two subunits are contained. This assumption is sustained by the finding that combined renaturation from equal volumes of eluates containing p50 and p 65 allows complete reconstitution of the heterotetramer. The amount of p50 should therefore reflect the amount of p65.

The amount of $I_{\kappa} B$ was calculated from its inhibitory activity toward a known amount of NF- $\mathrm{KB}$ heterotetramer. Assuming a stoichiometric interaction between I $\mathrm{K} B$ and heterotetramer, a half-maximal inhibition should indicate an equimolar amount of IKB and the heterotetramer (see Fig. 3, reaction 6).
Protein-protein reactions and electrophoretic mobility shift assays

The protein subunits were incubated prior to the DNA-binding reaction. The latter was used to monitor the interactions of protein subunits by (1) changes in protein-DNA complex mobility and (2) inhibition or (3) activation of DNA binding. Protein subunits of NF- $\mathrm{KB}$ were reacted with each other in subnanogram amounts in $10 \mu$ l renaturation buffer $[100 \mathrm{mM} \mathrm{NaCl}, 10$ $\mathrm{mM} \mathrm{KCl}, 20 \mathrm{~mm}$ Tris- $\mathrm{HCl}$ at $\mathrm{pH} 7.5,2$ mM EDTA, 2 mm dithiothreitol, $10 \%$ (vol $/ \mathrm{vol}$ ) glycerol, $0.1 \%$ (vol/vol) NP-40, and 0.1 $\mathrm{mM}$ phenylmethyl sulfonylfluoride]. After $10 \mathrm{~min}$ at room temperature, $10 \mu \mathrm{l}$ of DNA-binding mix was added $[150 \mathrm{mM} \mathrm{NaCl}$, $20 \mathrm{~mm} \mathrm{KCl}, 30 \mathrm{~mm}$ Tris- $\mathrm{HCl}$ at $\mathrm{pH} \mathrm{7.5,16 \%} \mathrm{(vol/vol)} \mathrm{glycerol,}$ $20 \mu \mathrm{g}$ bovine serum albumin, $0.2 \%$ (vol/vol) NP-40, $250 \mathrm{ng}$ poly[d(I-C)] (Sigma), and 10,000 cpm (Cerenkov) ${ }^{32}$ P-labeled oligonucleotide (see above)l. DNA-binding reactions were allowed for $15 \mathrm{~min}$ at room temperature. Samples were analyzed on $4 \%$ native polyacrylamide gels using the conditions described by Sen and Baltimore (1986a).

\section{Determination of dissociation constants}

The experiment was performed as described in detail elsewhere (Zabel et al. 1991), with the modification that the heterotetramer was obtained after combined renaturation of gel-purified p50 and p65 (Baeuerle and Baltimore 1989) with the modification described above.

\section{Acknowledgments}

We are indebted to Susi Kunz and Claudia Winter for excellent technical assistance, Dr. Martine Collart for stimulating discussions, Ralf Schreck, Dr. Lienhard Schmitz, and Cathy Schindewolf for helpful comments on the manuscript, Andrea Oswald and Dr. Georg Arnold for synthesizing oligonucleotides, Ulrike Zabel for purified ІкB, Ralf Schreck and Gerald Messer for cell extracts, and Professor Ernst-Ludwig Winnacker for his continuous support. This study was supported by a grant from the Bundesministerium für Forschung und Technologie and is part of the doctoral thesis of M.B.U.

The publication costs of this article were defrayed in part by payment of page charges. This article must therefore be hereby marked "advertisement" in accordance with 18 USC section 1734 solely to indicate this fact.

\section{References}

Baeuerle, P.A. and D. Baltimore. 1988a. IкB: A specific inhibitor of the NF-kB transcription factor. Science 242: 540-546.

. 1988b. Activation of DNA-binding is an apparently cytoplasmic precursor of the NF-кB transcription factor. Cell 53: $211-217$.

1989. A $65-\mathrm{kD}$ subunit of active NF-kB is required for inhibition of NF-кB by IкB. Genes Dev. 3: 1689-1698.

. 1990. The physiology of the NF- $\mathrm{B}$ B transcription factor. In Molecular aspects of cellular regulation (ed. P. Cohen and J.G. Foulkes), vol. 6. Elsevier/North-Holland Biomedical Press, Amsterdam. (In press.)

Baeuerle, P.A., M. Lenardo, J.W. Pierce, and D. Baltimore. 1988. Phorbol-ester-induced activation of the NF- $\mathrm{KB}$ transcription factor involves dissociation of an apparently cytoplasmic NF-кB/inhibitor complex. Cold Spring Harbor Symp. Quant. Biol. 53: 789-798.

Baldwin, A.S. and P.A. Sharp. 1988. Two transcription factors, NF- $\mathrm{B}$ and $\mathrm{H} 2 \mathrm{TF} 1$, interact with a single regulatory se- 
quence in the class I major histocompatibility complex promoter. Proc. Natl. Acad. Sci. 85: 723-727.

Collart, M.A., P.A. Baeuerle, and P. Vassalli. 1990. Regulation of tumor necrosis factor alpha transcription in macrophages: Involvement of four $\kappa \mathrm{B}$-like motifs and of constitutive and inducible forms of NF-кB. Mol. Cell. Biol. 10: 1498-1506.

Ghosh, S. and D. Baltimore. 1990. Activation in vitro of NF-kB by phosphorylation of its inhibitor, IкB. Nature 344: 678682.

Israel, A., O. Le Bail, D. Hatat, J. Piette, M. Kieran, F. Logeat, D. Wallach, M. Fellous, and P. Kourilsky. 1989. TNF stimulates expression of mouse $\mathrm{MHC}$ class I genes by inducing an NF-kB-like enhancer binding activity which displaces constitutive factors. $E M B O$ J. 8: 3793-3800.

Kawakami, K., C. Scheidereit, and R.G. Roeder. 1988. Identification and purification of a human immunoglobulin enhancer binding protein (NF- $\mathrm{kB}$ ) that activates transcription from a human immunodeficiency virus type I promoter in vitro. Proc. Natl. Acad. Sci. 85: 4700-4704.

Kieran, M., V. Blank, F. Logeat, J. Vandekerckhove, F. Lottspeich, O. Le Bail, M.B. Urban, P. Kourilsky, P.A. Baeuerle, and A. Israel. 1990. The DNA-binding subunit of NF-kB is identical to factor KBFl and homologous to the rel oncogene product. Cell 62: 1007-1018.

Lenardo, M. and D. Baltimore. 1989. NF-кB: A pleiotropic mediator of inducible and tissue-specific gene control. Cell 58: $227-229$.

Lenardo, M., J.W. Pierce, and D. Baltimore. 1987. Protein binding sites in Ig gene enhancers determine transcriptional activity and inducibility. Science 236: $1573-1577$.

Libermann, T.A. and D. Baltimore. 1990. Activation of interleukin- 6 gene expression through the NF- $\mathrm{KB}$ transcription factor. Mol. Cell. Biol. 10: 2317-2334.

Meisterernst, M., I. Gander, L. Rogge, and E.-L. Winnacker. 1988. A quantitative analysis of nuclear factor I/DNA interactions. Nucleic Acids Res. 16: 4419-4435.

pierce, J.W., M. Lenardo, and D. Baltimore. 1988. An oligonucleotide that binds nuclear factor NF-kB acts as a lymphoidspecific and inducible enhancer element. Proc. Natl. Acad. Sci. 85: 1482-1486.

Sen, R. and D. Baltimore. 1986a. Multiple nuclear factors interact with the immunoglobulin enhancer sequence. Cell 46: $705-716$.

- 1986b. Inducibility of $\kappa$ immunoglobulin enhancerbinding protein NF- $\mathrm{BB}$ by a posttranslational mechanism. Cell 47: 921-928.

Shirakawa, F. and S.B. Mizel. 1989. In vitro activation and nuclear translocation of NF- $\mathrm{KB}$ catalyzed by cyclic AMP-dependent protein kinase and protein kinase C. Mol. Cell. Biol. 9: 2424-2430.

Zabel, U. and P.A. Baeuerle. 1990. Purified human IkB can rapidly dissociate the complex of the NF- $\mathrm{B}$ transcription factor with its cognate DNA. Cell 61: 255-270.

Zabel, U., R. Schreck, and P.A. Baeuerle. 1991. DNA-binding of purified transcription factor NF-kB: Affinity, specificity, $\mathrm{Zn}^{2+}$ dependence and differential half site recognition. $J$. Biol. Chem. (in press). 


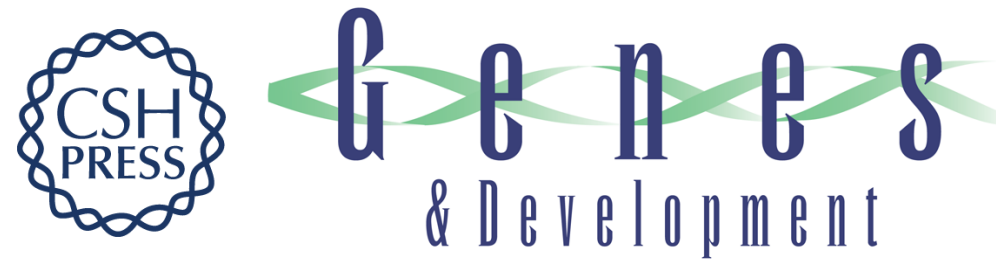

\section{The 65-kD subunit of NF-kappa B is a receptor for I kappa B and a modulator of DNA-binding specificity.}

M B Urban and P A Baeuerle

Genes Dev. 1990, 4:

Access the most recent version at doi:10.1101/gad.4.11.1975

References This article cites 19 articles, 9 of which can be accessed free at:

http://genesdev.cshlp.org/content/4/11/1975.full.html\#ref-list-1

License

Email Alerting

Service

Receive free email alerts when new articles cite this article - sign up in the box at the top right corner of the article or click here.

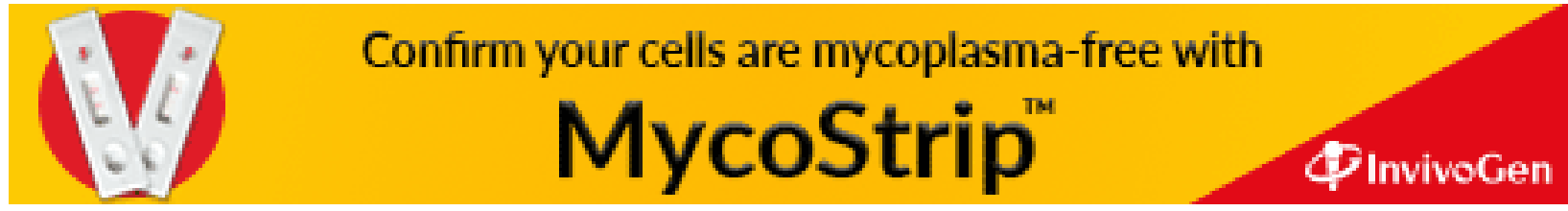

